\title{
MODELO PEDAGÓGICO DE APRENDIZAGEM BASEADA EM PROJETOS PARA UMA FORMAÇÃO TÉCNICA CONTEXTUALIZADA
}

\section{Marta Liliana Estruch \\ Abadie* \\ Ema Luz Anatibia Leiva** \\ Sofía Carolina Vergara Sanfuentes** *}

\section{*Diretora Acadêmica da Sociedade Nacional de Agricultura (SNA Educa). Licenciada em Educação. Professora do Estado de Matemática e Computação do Ensino Médio. Pós-graduação em Informática de Gestão (Inges). Santiago, Chile. E-mail: mestruch@snaeduca.cl \\ **Coordenadora Acadêmica da SNA Educa. Licenciada em Educação. Professora do Estado do Ensino Médio Técnico Profissional. Mestrado em Direção e Desenvolvimento Local. Santiago, Chile. E-mail: ema.anatibia@snaeduca.cl}

***Coordenadora Acadêmica da SNA Educa. Licenciada em Educação. Professora do Estado de Ensino Médio CientíficoHumanista, com ênfase em Biologia. Santiago, Chile. E-mail: svergara@snaeduca.cl

Recebido para publicação em 27.7.2018

Aprovado em 16.10.2018

\section{Resumo}

O artigo revela a experiência de instalar e implementar a Metodologia Baseada em Projetos (PBL) em centros profissionais de educação técnica no Chile. Isso permitiu sistematizar práticas voltadas para a melhoria da qualidade da educação, formando um modelo pedagógico que pode ser replicado. Ademais, são descritas algumas das ações pedagógicas intencionais importantes para permitir que os alunos aprendam na diversidade, trabalhando uns com os outros, estimulando seu crescimento emocional, pessoal e intelectual.

Palavras-chave: Aprendizagem Baseada em Projetos. Educação média técnico-profissionalizante. Metodologias ativas de aprendizagem. Formação geral. Formação diferenciada.

\section{Introdução}

A diversidade é um elemento que o sistema de educação formal adiou por muito tempo, causando uma grande desigualdade, embora todos tenham acesso a ele (CUBERO, 2008). Esse sistema reflete certos padrões cognitivos e culturais próprios de seus criadores, deixando de fora um número considerável de pessoas com diferentes elementos culturais, o que provoca um efeito inverso ao desejado, aumentando a distância dentro do sistema educacional.

Isso requer que os professores modifiquem suas práticas pedagógicas e as direcionem à integração das particularidades de cada aluno (LÓPEZ, 1997), a fim de criar vínculos efetivos entre a bagagem cultural destes com os conteúdos que devem ser abordados nos programas estabelecidos, gerando, assim, um aprendizado significativo (ONTORIA, 1999). 
Este cenário, acentuado por um mundo globalizado e interconectado, exige mudanças na forma como o trabalho docente se desenvolve com os alunos, tornando necessária a incorporação de estratégias e metodologias que facilitem a participação de crianças e jovens nos processos de ensino-aprendizagem, desenvolvendo suas capacidades de uma maneira integral. É assim que as metodologias ativas de ensino-aprendizagem, como o Trabalho Cooperativo e a Aprendizagem Baseada em Projetos (ABP), tornam-se uma resposta pertinente e eficaz para gerar aprendizagens duradouras ao longo da vida em contextos de maior diversidade.

Essas metodologias favorecem o objetivo final da educação: garantir que todas as pessoas desenvolvam seus potenciais e talentos, independentemente de suas condições pessoais, socioeconômicas e culturais, a fim de desenvolver suas habilidades cognitivas e afetivas, para que possam pensar de maneira reflexiva e resolver por si sós os problemas que as afetam, permitindo assim melhorar sua qualidade de vida.

A abordagem
do projeto
possibilita a
articulação da
formação e das
metodologias
utilizadas pelos
professores

O sistema escolar chileno não está alheio a essa realidade diversa e globalizada, assumindo-a em todos os níveis educacionais que compõem os 12 anos de escolaridade obrigatória, sendo os últimos dois anos o ciclo diferenciado que oferece dois percursos de formação possíveis. De um lado, o Ensino Médio Científico-Humanístico e, de outro, o Ensino Médio Técnico-Profissionalizante.

O Ensino Médio Técnico-Profissionalizante, no Chile, com uma trajetória de mais de 100 anos, concentra atualmente 39\% das matrículas do último ano letivo, cuja orientação é formar jovens em um campo de trabalho específico, tornando-se uma área de preparação inicial para o mundo do trabalho e, mais amplamente, uma alternativa de formação integral para a vida adulta.

Essa preparação se constrói com um currículo que articula o domínio das competências técnicas ou próprias da especialidade (Formação Diferenciada) com as competências transversais e os conteúdos da Formação Geral da Educação Média. Isso exige um processo interdisciplinar de ensino-aprendizagem entre os dois tipos de formação, com o objetivo de desenvolver as competências que possibilitem aos estudantes que optam por essa modalidade inserir-se adequadamente na sociedade por meio do campo de trabalho ou da continuidade dos estudos.

A abordagem do projeto possibilita a articulação da formação e das metodologias utilizadas pelos professores. Isso implica, entre outras coisas, definir os objetivos comuns às diferentes áreas envolvidas e estabelecer um plano apropriado ao tempo, aos meios e recursos disponíveis para o desenvolvimento de cada projeto.

A Sociedade Nacional de Agricultura (SNA Educa) aspira formar pessoas integrais, com uma clara formação de valor, capacidade empreendedora definida e competência para enfrentar novas situações e solucionar problemas, nos campos pessoal e profissional. Esse propósito privilegia o uso da tecnologia, a visão global e 
a proatividade como competências essenciais, materializadas por intermédio dos programas de Formação Geral e Diferenciada.

A Corporação Educacional SNA Educa, com 42 anos de experiência na formação média técnica-profissionalizante, com ênfase no setor rural e em contextos de vulnerabilidade, administra atualmente uma Rede de 20 centros educacionais com ampla cobertura em todo o país; estes centros acolhem mais de 11 mil jovens capacitados em diferentes especialidades relacionadas principalmente aos setores: Agrícola, Industrial, Alimentício e Mineração.

O Modelo Pedagógico implementado nos estabelecimentos SNA Educa se sustenta no protagonismo do aluno, o que implica uma estrutura que inclui diferentes níveis de ordenação, desde o equipamento, o design e a distribuição da infraestrutura, até a interação professor-aluno, com foco em um efetivo desenvolvimento integral dos alunos, facilitando, com isso, sua futura inserção laboral, o desenvolvimento de uma empresa ou a busca de estudos.

Figura 1 - Esquema de progressão para a instalação da metodologia ABP na Rede SNA Educa

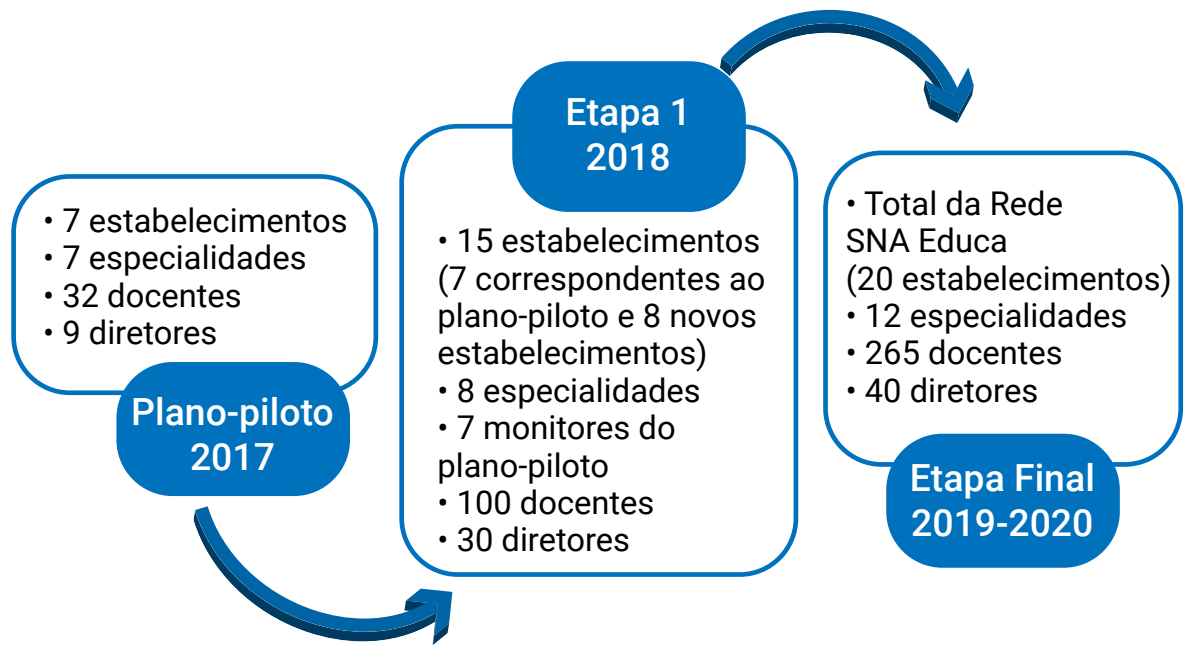

Fonte: Elaboração própria.

Em função de a metodologia ABP ser uma resposta relevante aos desafios de formação que a SNA Educa enfrenta, foi decidido, como diretriz estratégica, instalá-la progressivamente nos centros educacionais que compõem sua rede, como mostrado no esquema anterior.

A seguir, a experiência de dois anos para instalar e implementar a metodologia ABP em 15 centros de educação técnico-profissionalizantes da SNA Educa - Chile. 


\section{Instalação da ABP nos centros SNA Educa}

O novo contexto da escola em um mundo globalizado se contrasta com o clássico processo educacional homogeneizador dos indivíduos e simplificador da realidade (LÓPEZ, 1997), ao passo que, no mundo, ocorre exatamente o oposto, a sociedade torna-se mais complexa, o que exige novos desafios aos processos de ensino; consequentemente, as pessoas devem ser capacitadas com base em suas próprias capacidades e características culturais em conexão com sua realidade para serem ativamente inseridas em um mundo dinâmico e sistêmico.

As competências

transversais contribuem significativamente para 0 desenvolvimento das pessoas
Neste cenário, as metodologias ativas ganham força e são pertinentes, pois favorecem aos estudantes que assumem um papel de liderança no aprendizado e desenvolvimento pessoais. Essa mudança no processo de ensino-aprendizagem proporciona uma oportunidade para que os jovens desenvolvam as habilidades demandadas pela sociedade atual, tornando-se reflexivos, criativos, com conhecimento técnico, capazes de aprender ao longo da vida, trabalhando cooperativamente e se comunicando de forma eficaz.

Essas mudanças representam desafios para o sistema de ensino no que tange ao desenvolvimento de habilidades flexíveis ou competências transversais, e já em 2008, Wanger - codiretor do grupo "Mudança de liderança", de Harvard - identificou sete habilidades básicas para se adaptar ao novo cenário de trabalho: pensamento crítico e resolução de problemas; colaboração por intermédio de redes e liderança por influência; agilidade e adaptabilidade; iniciativa e espírito empreendedor; comunicação eficaz, oral e escrita; acesso e análise de informações; e curiosidade e imaginação.

Essa opinião também encontra apoio no Fórum de Davos, que identifica como as 10 Melhores Habilidades para trabalhadores de 2020 as seguintes: resolução de problemas complexos, pensamento crítico, criatividade, gestão de pessoas, coordenação com outros, inteligência emocional, análise e tomada de decisão, orientação ao serviço, negociação e flexibilidade cognitiva.

A capacidade de tomar decisões, o gerenciamento do estresse, a flexibilidade, a iniciativa ou a motivação são características que permitirão que os alunos se desenvolvam em um ambiente organizacional para além do conhecimento técnico. As competências transversais contribuem significativamente para o desenvolvimento das pessoas e influenciam diretamente a empregabilidade, sendo um dos principais pontos de atenção em entrevistas de emprego e processos de seleção.

Em resumo, é possível agrupar essas novas demandas na formação de técnicos em:

1. Aprender a aprender: é a habilidade de se formar ao longo dos anos, de modo autônomo. 
2. Adaptação: é a capacidade de se desenvolver em diferentes ambientes de trabalho, explorando todas as capacidades em diversos contextos (de empresas, setores ou países).

3. Trabalho em equipe: é saber como adotar um papel positivo, colocando o conhecimento e as capacidades pessoais a serviço de um trabalho no qual vários trabalhadores estão envolvidos e que geram sinergias, capacidade de liderança, etc.

4. Resolução: aplicar a lógica e tomar decisões em diferentes contextos, avaliar as decisões e ser capaz de corrigir erros. Inclui a gestão de projetos com colaboradores.

A Aprendizagem Baseada em Projetos não é uma metodologia recente, muito pelo contrário, um dos marcos mais conhecidos foi no início do século XX, com William Heart Kilpatrick, em 1918, com a publicação de sua obra O Método de Projetos. Contudo, parece que seu uso hoje em dia faz mais sentido na prática pedagógica, pois gera uma participação mais ativa dos alunos e, consequentemente, um maior envolvimento deles (sem muitas vezes estarem cientes de que estão vivenciando um significativo processo de ensino-aprendizagem).

Por outro lado, a ABP contribui e se torna uma oportunidade para conhecer os temas de Formação Geral e Formação Diferenciada (Técnica). Isso possibilita o enfoque em ações pedagógicas baseadas em aprendizagens comuns e complementares, favorecendo a aquisição de uma aprendizagem de forma duradoura, promovendo um ensino desafiador e ligado às necessidades e características dos alunos, conectando-os com o mundo real por meio de um projeto. Isso provoca maior motivação e autonomia dos estudantes, assim como importantes habilidades como pesquisa, trabalho cooperativo e resolução de problemas tão necessários para abordar adequadamente sua colocação profissional ou estudos complementares. Trabalhar interdisciplinarmente em torno de um projeto também se torna uma instância de colaboração aberta e flexível entre os professores, pois fornece espaços de aprendizagem que facilitam o máximo desenvolvimento das habilidades de cada aluno e equipes de trabalho.

A implementação da metodologia de Aprendizagem Baseada em Projetos na instituição propôs que cada estabelecimento assumisse um papel de liderança no processo. Ou seja, considerou como eixo central que os estabelecimentos possuíam autonomia em cada uma de suas etapas, desde a análise e revisão curricular, a capacitação e atualização de professores e a elaboração de material didático e instrumentos de avaliação, entre outros. 
Figura 2 - Diagrama de análise curricular para implementar a ABP na Rede SNA

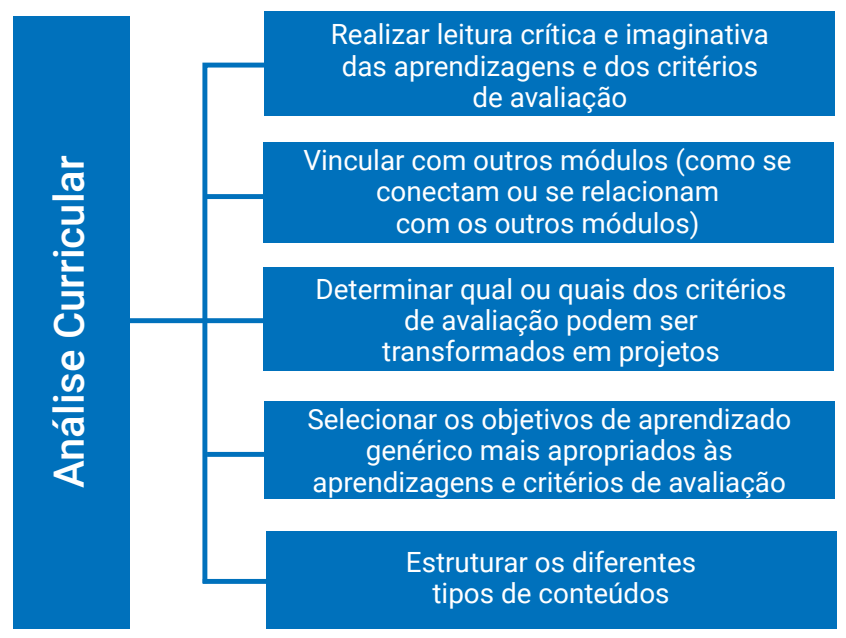

Fonte: Elaboração própria.

Abordar a instalação da Aprendizagem Baseada em Projetos intencionalmente nos estabelecimentos da instituição como estratégia pedagógica responde ao fato de este enfoque, além de se adaptar especialmente bem a essa demanda formativa, uma vez que facilita o desenvolvimento conjunto de competências transversais exclusivamente técnicas, promove uma atitude positiva nos alunos em relação à aprendizagem e à formação.

Em seguida, são mencionadas as ações que foram decisivas na implementação da metodologia de aprendizagem baseada em projetos como abordagem de ensino-aprendizagem em cada um dos centros educacionais:

a. Formação de uma equipe de professores e seleção de objetivos de aprendizagem para trabalhar. Em cada centro educacional ou grupo de centros educacionais, as equipes incluem professores que estão ensinando diretamente aos estudantes, tanto de Formação Geral quanto de Formação Diferenciada (ou de especialidade), tanto quanto possível do mesmo nível educacional. É essencial que a equipe tenha também um diretor pedagógico, que lidere a equipe de professores e facilite a implementação da ABP em cada um dos centros educacionais.

b. Análise das habilidades técnicas ou objetivos genéricos de aprendizagem expressos nos perfis de graduação e integração do currículo de Formação Geral e Diferenciada (ou de especialidade), por meio da identificação de pontos de convergência que facilitem o alcance das competências expressas nos perfis de egresso.

Por outro lado, as equipes de professores que trabalham interdisciplinarmente por meio de um projeto devem ter claras as metas comuns e individuais a serem alcançadas, como:

- Um grau de complexidade de aprendizagem adequado aos programas de estudo e nível educacional. 
- A cobertura das aprendizagens definidas nos planos e programas de estudo.

- A abordagem de uma aprendizagem, capacidade ou objetivo transversal de mais de uma área disciplinar, alcançando maior impacto.

c. Instalação da metodologia de Aprendizagem Cooperativa para o trabalho em sala de aula com os alunos, em função de este ser um fator-chave de sucesso para a posterior implementação da ABP. Pretende-se, nessa fase, no intuito de orientar o trabalho docente em sala de aula, implementar um plano de aula que explique, por meio de diferentes estratégias e técnicas de trabalho cooperativo, que os alunos desenvolvam a maior parte do tempo como uma equipe, na qual devem necessariamente ser ativos e interagir com os outros, assumindo papéis diferentes. Embora o design da aula ou plano de aula facilite o trabalho docente, deve permitir flexibilidade para ser adaptado à realidade dos alunos e ao contexto do centro.

d. Instalação da metodologia ABP, com base no trabalho interdisciplinar para determinar a temática dos projetos a serem desenvolvidos com os alunos, a elaboração de material didático e instrumentos de avaliação, a fim de identificar as condutas anteriores que os alunos devem ter para sua resolução. Essa fase, independentemente do modelo com suas diferentes etapas utilizadas, requer uma grande capacidade do professor para adaptar o modelo com flexibilidade à realidade do centro.

e. Operabilidade da equipe de ensino da ABP. Em relação ao tempo de coordenação e planejamento, é importante ter um cronograma que permita o trabalho dos professores para planejamento e acompanhamento. Nesse aspecto, é necessário ser flexível adaptando-se às exigências do projeto (ajuste de horários, espaços, móveis que respondem mais a funções do que a papéis, etc.).

\section{Implementação da metodologia ABP na aula}

As metodologias ativas em sala de aula, em particular o desenvolvimento de projetos, propiciam a possibilidade de os alunos aprenderem de maneira abrangente acompanhados por seus professores. Nesse sentido, os aspectos relevantes para sua implementação em sala de aula foram os seguintes:

a. Uso de um modelo como recurso de ensino. Isso permite que os alunos se apropriem da metodologia do projeto e desenvolvam habilidades técnicas integradas, objetivos genéricos e aprendizagens de formação geral.

O modelo que orienta a implementação da ABP na SNA Educa considera as seguintes fases:

A ocasião, momento em que o professor valoriza o potencial educativo de determinado tema, analisando os objetivos que podem surgir, a recepção que terá por parte dos alunos e o impacto na comunidade educativa. 
A intenção, fase em que o grupo de alunos, em conjunto com o professor, decide se irá realizar o projeto.

O olhar, design do projeto e seus possíveis itinerários, a partir deste momento o grupo começa a trabalhar no projeto.

A estratégia, pesquisa que identifica diferentes itinerários a serem seguidos pelos membros do grupo no desenvolvimento do projeto.

A ação, realização de um produto ou serviço final.

A arquitetura (fase transversal às cinco etapas anteriores), narração contínua do desenvolvimento do projeto em todas as suas fases.

A avaliação (fase transversal às cinco etapas anteriores), processo que combine a avaliação do professor com a autoavaliação e a coavaliação grupal.

O Quadro 1 apresenta a intervenção do professor e dos alunos em cada fase do modelo utilizado.

Quadro 1 - Planejamento de uma matéria com base no projeto ABP

\begin{tabular}{|c|c|c|}
\hline ETAPAS & AÇÕES DO PROFESSOR & AÇÕES DOS ESTUDANTES \\
\hline \multirow[b]{2}{*}{ A OCASIÃO } & \multicolumn{2}{|c|}{ SURPREENDER-SE } \\
\hline & $\begin{array}{l}\text { Nasce um projeto } \\
\text { Análise de viabilidade (FOFA/SWOT) }\end{array}$ & \\
\hline \multirow[b]{2}{*}{ A INTENÇÃO } & \multicolumn{2}{|c|}{ DECIDIR } \\
\hline & $\begin{array}{l}\text { Procura por impulsor } \\
\text { Resume impressões }\end{array}$ & $\begin{array}{l}\text { Nasce um projeto } \\
\text { Expressam vivências em relação às atividades realizadas } \\
\text { e compromissos que assumiram }\end{array}$ \\
\hline \multirow[b]{2}{*}{ O OLHAR } & \multicolumn{2}{|c|}{ DESENHAR O PROJETO (ITINERÁRIOS) } \\
\hline & $\begin{array}{l}\text { Ativa conhecimentos prévios, o que sabem os estudantes? } \\
\text { Formulação de problemas }\end{array}$ & Conhecimentos prévios: o que sabemos? \\
\hline \multirow[b]{2}{*}{ A ESTRATÉGIA } & \multicolumn{2}{|c|}{ PESQUISAR E FAZER } \\
\hline & $\begin{array}{l}\text { Design de pesquisa, linhas de trabalho } \\
\text { Gestão da pesquisa } \\
\text { Recursos necessários }\end{array}$ & $\begin{array}{l}\text { Propostas e linhas de pesquisa } \\
\text { Redação formal da proposta de pesquisa } \\
\text { Defesa das propostas }\end{array}$ \\
\hline \multirow[b]{2}{*}{ A AÇÃO } & \multicolumn{2}{|c|}{ ATUAR E MUDAR } \\
\hline & $\begin{array}{l}\text { Resume as propostas de ação apresentadas } \\
\text { Estima o impacto }\end{array}$ & $\begin{array}{l}\text { Produto do projeto } \\
\text { Propostas de ação }\end{array}$ \\
\hline \multirow[b]{2}{*}{ A ARQUITETURA } & \multicolumn{2}{|c|}{ TRANSVERSAL A TODO O PROCESSO } \\
\hline & Determina o formato para a arquitetura & $\begin{array}{l}\text { Propõe a arquitetura do projeto: como coletar tudo que } \\
\text { acontece durante o projeto? }\end{array}$ \\
\hline \multirow[b]{2}{*}{ A AVALIAÇÃO } & \multicolumn{2}{|c|}{ TRANSVERSAL A TODO O PROCESSO } \\
\hline & $\begin{array}{l}\text { Avaliação contínua das aprendizagens, do projeto e da } \\
\text { dinâmica relacional }\end{array}$ & Avaliação contínua e final (coavaliação e autoavaliação) \\
\hline
\end{tabular}

Fonte: VERGARA (2015).

Planejamento de turma. Sua finalidade é que os professores nela incorporem o modelo $A B P$, que se tornará o roteiro, que facilitará didaticamente os alunos a desenvolver e colocar em prática suas diversas capacidades em torno da geração de um projeto. 
Figura 3 - Planejamento de aula

\begin{tabular}{|c|c|c|c|c|}
\hline \multicolumn{5}{|c|}{ MATÉRIA / DISCIPLINA / MÓDULO } \\
\hline \multicolumn{5}{|c|}{ CURSO / GRUPO } \\
\hline \multicolumn{5}{|l|}{ TEMPO } \\
\hline \multicolumn{5}{|c|}{$\begin{array}{l}\text { Horas totais dedicadas ao projeto: } \\
\text { Horas semanais dedicadas ao projeto: }\end{array}$} \\
\hline \multicolumn{5}{|c|}{ APRENDIZAGENS ESPERADAS E CRITÉRIOS DE AVALIAÇÃO } \\
\hline \multirow[t]{3}{*}{$\begin{array}{l}\text { Aprendizagem } \\
\text { esperada }\end{array}$} & \multicolumn{2}{|c|}{$\begin{array}{l}\text { Critérios de } \\
\text { avaliação } \\
\mathrm{AE}\end{array}$} & \multicolumn{2}{|c|}{$\begin{array}{l}\text { Objetivos genéricos } \\
\text { de aprendizagem } \mathrm{AE}\end{array}$} \\
\hline & \multicolumn{2}{|l|}{ CA1 } & & \\
\hline & \multicolumn{2}{|l|}{ CA "n" } & & \\
\hline Conteúdos da $\mathrm{AE}$ & Conceitos & Proce & imentos & $\begin{array}{l}\text { Atitudes } \\
\text { profissionais }\end{array}$ \\
\hline
\end{tabular}

Fonte: Elaboração própria.

b. Planejamento geral de um projeto. Detalha os módulos ou matérias envolvidas, os objetivos abordados (gerais e específicos) e todos os detalhes que mostram uma sinopse do processo e do trabalho interdisciplinar a ser realizado pelos professores nos diferentes centros.

Figura 4 - Planejamento geral de um projeto

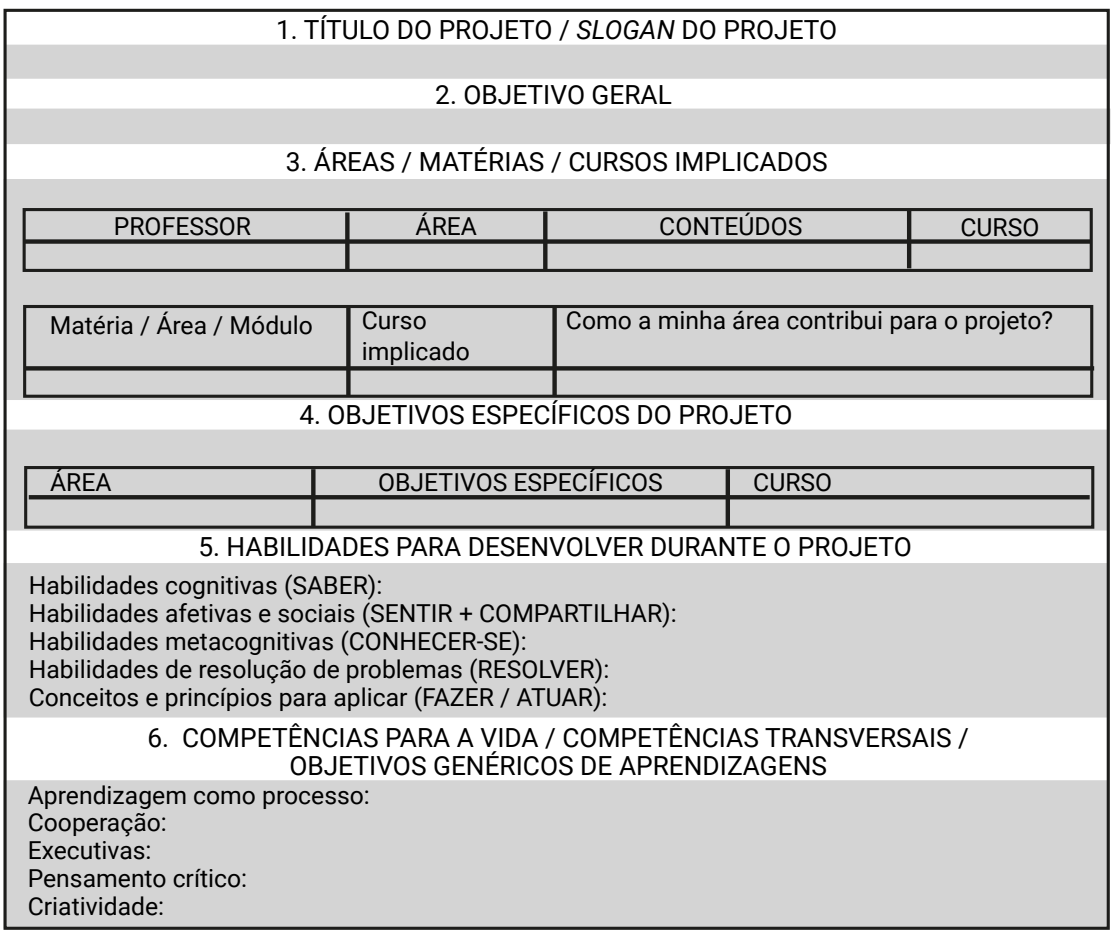

Fonte: Elaboração própria. 
c. Acompanhamento na implementação. Monitoramento e acompanhamento dos principais marcos, por meio de reuniões sobre o progresso, presenciais e virtuais, visitas de acompanhamento às equipes docentes, mais relatórios sobre o progresso, com o objetivo de avaliar os níveis de cumprimento das diferentes etapas que levam em conta o alcance dos objetivos traçados na execução do projeto.

d. Contextualização dos projetos. Os projetos desenvolvidos pelos alunos estão relacionados à realidade do contexto social ou profissional que é específico do estabelecimento. Isso ajuda os alunos a se envolverem mais e, portanto, ocuparem o papel de protagonistas e conseguirem colocar seus conhecimentos, habilidades e atitudes à prova, além de estarem mais receptivos a novos aprendizados e soluções. Exemplos de projetos desenvolvidos pela SNA Educa:

Figura 5 - Exemplos de Projetos ABP desenvolvidos pela SNA Educa
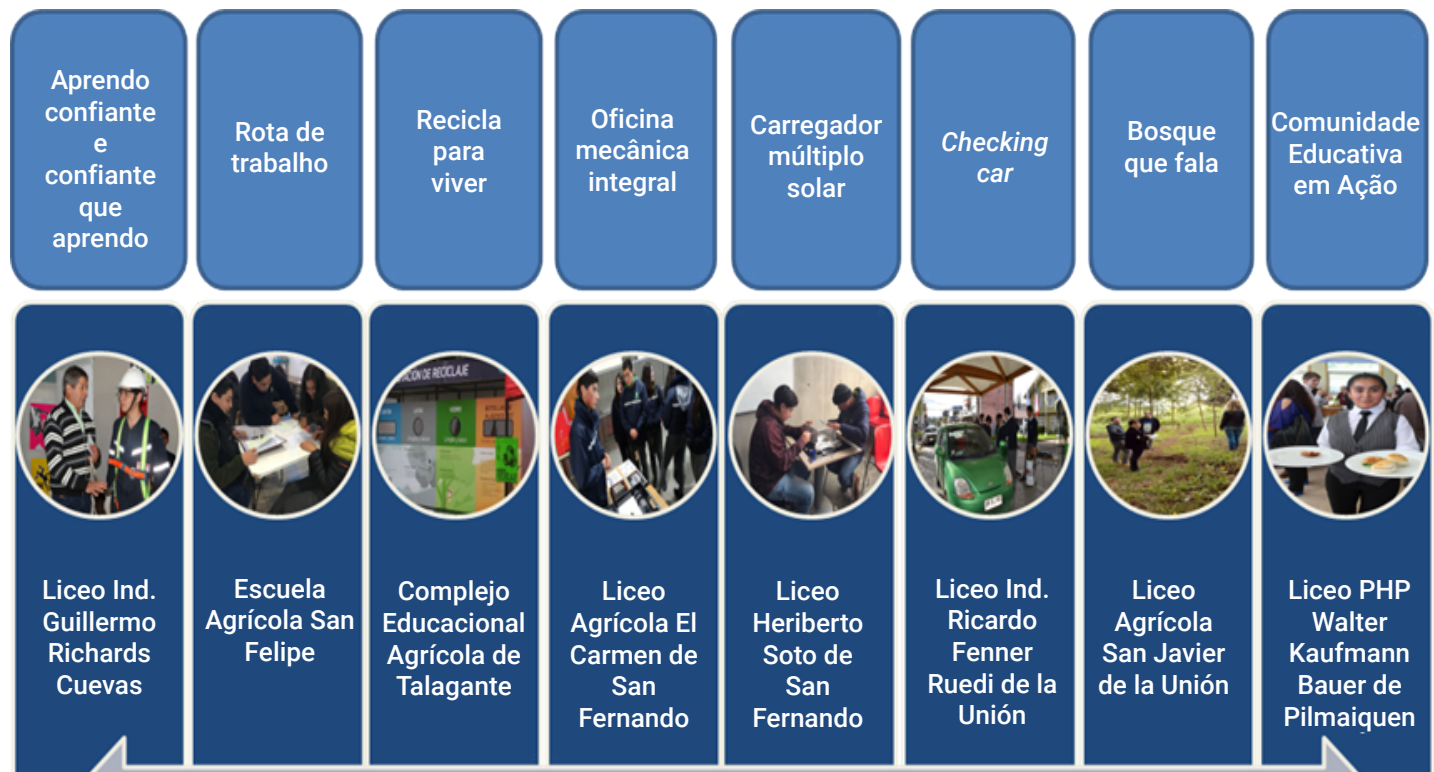

Liceo Ind.

Guillermo

Richards

Cuevas
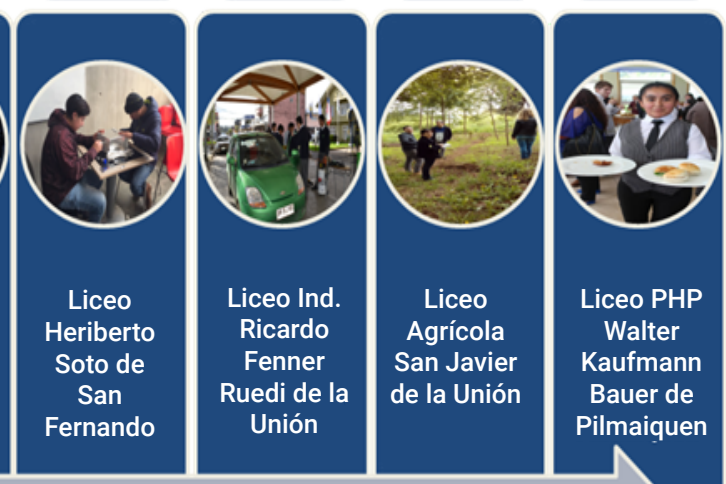

Liceo

Agrícola El

Carmen de

San

Fernando

Desenvolvimento de Competências Transversais e Articulação Curricular
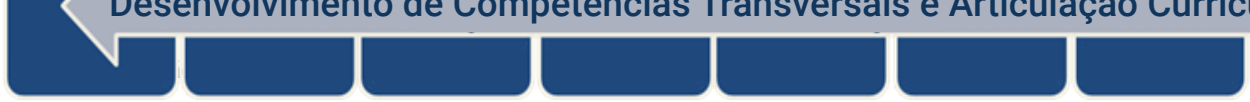

Fonte: Elaboração própria. 


\section{Avaliação no processo de geração de um projeto}

É importante mencionar que o estágio de "avaliação" é realizado transversalmente ao longo do processo do projeto, pois proporciona continuidade, motivação e envolvimento na aprendizagem dos jovens.

Os critérios de avaliação especificam o nível de realização referente aos resultados da aprendizagem, descrevem o que se deseja alcançar em todas as suas dimensões (conceitual, procedimental e atitudinal).

A síntese do processo de avaliação que as equipes de professores de cada centro abordam é apresentada a seguir:

\section{Figura 6 - Etapas do processo de avaliação}

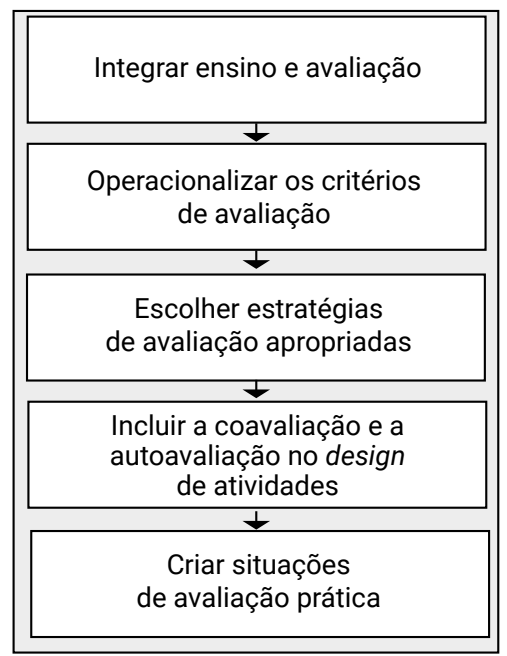

Fonte: Elaboração própria

As várias instâncias de avaliação do professor e do aluno são apresentadas a seguir:

\section{Quadro 2 - Função da avaliação durante o processo de aprendizagem}

\begin{tabular}{|l|l|}
\hline $\begin{array}{l}\text { A avaliação deve servir para estimular a reflexão de todos os participantes sobre a aprendizagem. Deve } \\
\text { ser um elemento que esteja presente durante todo o processo e combine a avaliação do educador com a } \\
\text { autoavaliação e a coavaliação grupal. }\end{array}$ & ALUNO \\
\hline PROFESSOR & $\begin{array}{l}\text { Avaliação contínua (serve de base } \\
\text { para a reflexão prévia à reunião de } \\
\text { avaliação semanal, quinzenal, etc.) }\end{array}$ \\
\hline $\begin{array}{l}\text { Avaliação contínua (instrumentos, agentes, temporalização). Serve guia de trabalho para a sessão de avaliação semanal, quinzenal, } \\
\text { entre outras. }\end{array}$ & $\begin{array}{l}\text { Avaliação final (serve de guia para a } \\
\text { reunião de avaliação final) }\end{array}$ \\
\hline $\begin{array}{l}\text { Avaliação dos resultados de aprendizagem (com expressão de } \\
\text { instrumentos, agentes, temporalização, se nenhuma rubrica for usada) }\end{array}$ & \\
\hline $\begin{array}{l}\text { Avaliação das fases do projeto (dos recursos, da temporalização, dos } \\
\text { agrupamentos, técnicas e dinâmicas empregadas) }\end{array}$ & \\
\hline $\begin{array}{l}\text { Avaliação da dinâmica relacional (funcionamento das equipes, papel } \\
\text { do docente, agentes comunitários, etc.) }\end{array}$ & \\
\hline
\end{tabular}


Coexistem na ABP uma variedade de suportes, temporalidades e participantes envolvidos na avaliação:

- Alguns dos suportes utilizados são portfólios, diários de aprendizagem, questionários, mapas conceituais, alvo de avaliação da equipe cooperativa, os Seis Chapéus de Bono, diagramas de fluxo, dramatização de papéis, questões abertas, questões de múltipla escolha, rubricas de avaliação de produto, etc.

- Quanto ao cronograma, a avaliação é realizada com frequências diferentes: diária, semanal, quinzenal, mensal e até o final do projeto.

- Os níveis de agrupamento são considerados de acordo com os assuntos a serem avaliados, ou seja, o aluno é avaliado individualmente, assim como o grupo de trabalho e o grupo do curso.

Finalmente, o professor avalia o próprio processo de ensino para sustentar ou modificar suas intervenções pedagógicas a fim de atingir os objetivos de aprendizagem propostos no planejamento do projeto.

A importância do trabalho realizado não faria sentido se não considerássemos o impacto que teve nos alunos e professores.

A seguir, algumas opiniões coletadas por meio de entrevistas com os estudantes e docentes nas visitas de acompanhamento:

O trabalho colaborativo me ajudou a me conhecer (aluno do terceiro ano do Ensino Médio, especialidade Mecânica Automotiva, Liceo Agrícola el Carmen de San Fernando).

0 professor nos orienta e encontramos nossas próprias respostas (aluno do terceiro ano do Ensino Médio, especialidade Mecânica Industrial, Liceo Industrial Guillermo Richard Cuevas de San Felipe).

Todos aprendemos e percebemos que somos capazes de contribuir com o trabalho do grupo (aluna do terceiro ano do Ensino Médio, especialidade Mecânica Industrial, Liceo Industrial Guillermo Richard Cuevas de San Felipe).

Assumir um papel dentro do grupo de trabalho nos ajuda a nos organizar melhor, a economizar tempo e faz com que todos trabaIhem (aluno do quarto ano do Ensino Médio, especialidade Agrícola, Liceo Agrícola de San Felipe).

Demora mais tempo para organizar tudo, no entanto, melhores resultados e produtos são alcançados, além disso, os alunos aprendem mais (Professora de Ciências, Liceo Agrícola de San Felipe).

0 trabalho cooperativo ajudou a integrar estudantes que estavam à parte do curso (Professor de Inglês, Liceo Agrícola el Carmen de San Fernando).

É surpreendente ver as conclusões e questões que surgem dos alunos sendo desafiados pelo professor, aprendendo por si mesmos, alcançando um progresso significativo (Professor de Especialidade, Liceo Industrial Guillermo Richard Cuevas de San Felipe). 


\section{Considerações finais}

A Aprendizagem Baseada em Projetos é uma metodologia propícia à educação do século XXI, porque os alunos assumem um papel de liderança no processo de ensino-aprendizagem.

Além disso, acaba por ser uma metodologia relevante para a formação técnica, uma vez que facilita a aquisição de competências técnicas e laborais pelos jovens, ao se utilizar da combinação equilibrada entre teoria e prática.

A Aprendizagem

Baseada em

Projetos é uma

metodologia

propícia à

educação do

século XXI

No contexto em que a metodologia da ABP é desenvolvida, a aquisição e a prática das habilidades sociais, por parte dos estudantes, são facilitadas, fortalecendo sua formação integral, elevando a pertinência e a resposta às demandas do ambiente social e produtivo. Por outro lado, contribui de maneira importante para articular as diferentes disciplinas que compõem o currículo tanto de formação geral como de formação diferenciada, integração esta que é um pilar básico para se obter uma formação técnica de qualidade.

A partir da experiência na implementação da metodologia ABP, sugere-se o seguinte em relação aos aspectos de instalação e gestão:

Com respeito à Instalação:

- A metodologia requer uma mudança de paradigma na maneira de pensar de alguns professores, por isso a socialização com eles sobre os benefícios da ABP e seu papel de liderança na aplicação é primordial, assim como a disseminação do seu impacto e resultados. O sucesso na sua implementação requer a vontade dos docentes e diretores, uma vez que exige estar atualizado em suas práticas e conhecimentos, estar disposto a investigar e ter flexibilidade suficiente para trabalhar com outros professores.

- A análise curricular permite identificar os objetivos de aprendizagem mais compatíveis com a metodologia ABP.

- É essencial instalar previamente a metodologia de aprendizagem cooperativa.

- A implementação da metodologia ABP deve ser gradual, flexível e sistemática, é complementar a outras metodologias de aprendizagem, e não é para todos os conteúdos ou para todos os momentos.

Com respeito à Gestão:

- Demanda mais tempo para preparação e implementação. Os docentes que assumem um novo papel como facilitadores precisam de mais tempo para planejar e avaliar os processos, o que requer professores comprometidos e coesos como uma equipe de ABP. A maioria das equipes de ensino exigiu um tempo de ajuste para definir o tema e o andamento do projeto. A execução foi mais fluida nas equipes que tiveram cursos do mesmo nível educacional. 
- Um dos principais desafios é manter um registro de todas as fases. Somente com essa evidência será possível avaliar o progresso do projeto e o nível de realização da aprendizagem esperada.

- A operacionalidade do projeto dependerá de um planejamento detalhado e correto, como a liderança e o apoio da equipe de gerenciamento de cada centro.

- O acompanhamento é fundamental para as equipes que estão desenvolvendo um projeto pela primeira vez. Existe o risco de se concentrar no produto ou serviço final e deixar de lado os objetivos de aprendizagem planejados. Deve-se sempre estabelecer um propósito de aprendizagem.

Em relação aos benefícios obtidos com a instalação da metodologia:

- Os estudantes encontram significado na aprendizagem, porque, graças à ABP, aprendem fazendo em contextos que são conhecidos por eles, tornando a aprendizagem mais duradoura ao longo do tempo.

- Otimiza os tempos de formação, evitando repetir conteúdos e aprendizagens entre as disciplinas.

- Aumenta o desenvolvimento do pensamento crítico, a autonomia e a motivação por parte dos alunos.

- Gera apropriação do perfil de egresso da formação por parte dos professores.

- Fortalece as capacidades de alunos e professores por meio do trabalho cooperativo e interdisciplinar.

No intuito de garantir a continuidade da metodologia nos centros, sugerem-se três ações para melhorá-la, medir seu impacto e aperfeiçoá-la:

- Formalizar e sistematizar sua implementação no programa de estudos.

- Fortalecer, de maneira permanente, as competências dos docentes.

- Construir um banco ou repositório de projetos.

\section{Referências}

COLL, César. Desarrollo, aprendizaje y enseñanza en educación secundaria. Madrid: Graó: Ministerio de Educación Cultura y Deporte, Secretaría General de Educación y Formación Profesional, 2010.

CUBERO, Rosario et al. La educación a través de su discurso: prácticas educativas y construcción discursiva del conocimiento en el aula. Revista de Educación, Madrid, n. 346, p. 71-104, 2008. 
JOIKO, Sara; VÁSQUEZ, Alba. Acceso y elección escolar de familias migrantes en Chile: "No tuve problemas porque la escuela es abierta, porque acepta muchas nacionalidades" Calidad en la Educación, Santiago, n. 45, 2016.

KILPATRICK, William H. The project method. Teachers College Record, New York, v. 19, n. 4, p. 319-335, 1918.

LÓPEZ, Luis Enrique. La diversidad étnica, cultural y lingüística latinoamericana y los recursos humanos que la educación requiere. Revista Iberoamericana de Educación, p. 47-98, 1997.

ONTORIA, Antonio et al. El mapa conceptual como técnica cognitiva y su proceso de elaboración. In: ONTORIA, Antonio et al. Mapas conceptuales: una técnica para aprender. Madrid: Narcea, 1999. p. 31-51.

VERGARA, Juan José. Aprendo porque quiero: el Aprendizaje Basado en Proyectos (ABP): paso a paso. [S.I.]: Ediciones SM, 2015.

WAGNER, Tony. The global achievement gap: why even our best schools don't teach the new survival skills our children need: and what we can do about it. NewYork: Basic Books, 2008.

WORLD ECONOMIC FORUM. The future of jobs employment, skills and workforce strategy for the Fourth Industrial Revolution Global Challenge Insight Report. Geneva, 2016. 